\title{
Novel coronavirus infections in Jordan, April 2012: epidemiological findings from a retrospective investigation
}

\author{
B. Hijawi, ${ }^{1}$ M. Abdallat ${ }^{2}$ A. Sayaydeh, ${ }^{2}$ S. Alqasrawi, ${ }^{2}$ A. Haddadin, ${ }^{3}$ N. Jaarour, ${ }^{2}$ S. Alsheikh ${ }^{2}$ and T. Alsanouri $^{3}$
}

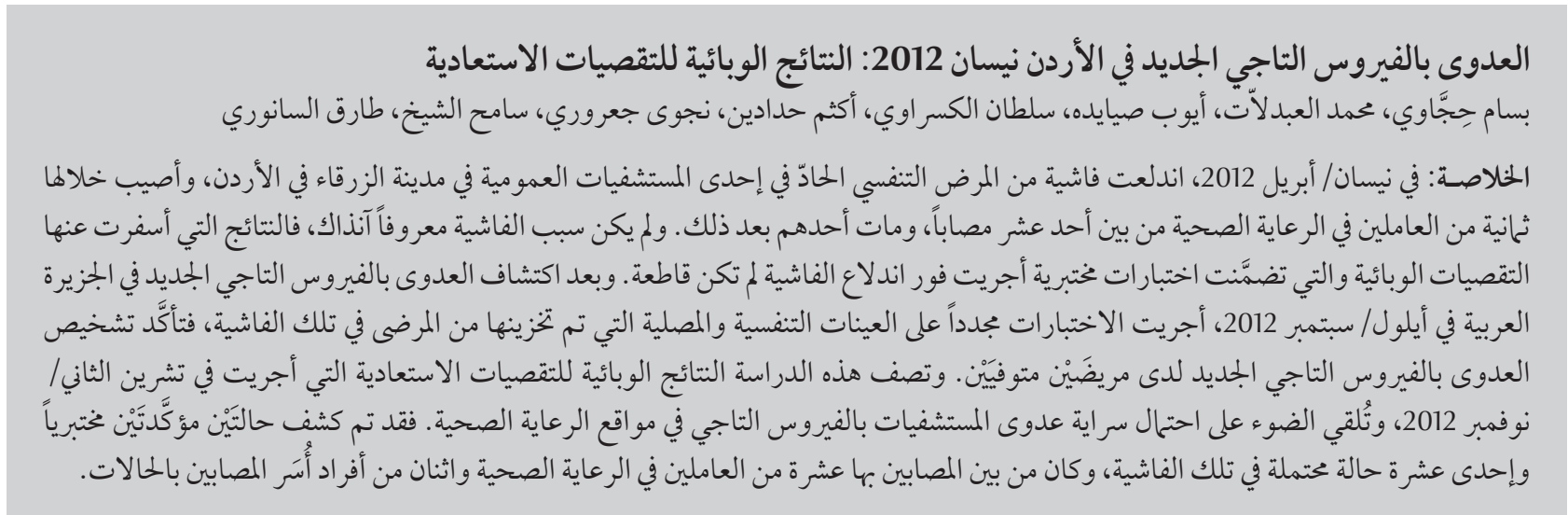

ABSTRACT In April 2012, an outbreak of acute respiratory illness occurred in a public hospital in Zarqa city, in Jordan; 8 health care workers were among the 11 people affected, 1 of who later died. The cause of the outbreak was unknown at the time and an epidemiological investigation including laboratory testing carried out immediately after the outbreak was inconclusive. Following the discovery of novel coronavirus infection (nCoV) in the Arabian peninsula in September 2012, stored respiratory and serum samples of patients from this outbreak were retested and the diagnosis of $\mathrm{nCoV}$ was confirmed in 2 deceased patients. This paper describes the epidemiological findings of retrospective investigation carried out in November 2012 and highlights the likelihood of nosocomial transmission of $\mathrm{nCoV}$ infection in a health-care setting. A total of 2 laboratory-confirmed and 11 probable cases were identified from this outbreak of whom 10 were HCWs and 2 were family members of cases.

Infections par le nouveau coronavirus en Jordanie, avril 2012 : résultats épidémiologiques d'une étude rétrospective

RÉSUMÉ En avril 2012, une flambée de maladies respiratoires aiguës a été observée dans un hôpital public de la ville de Zarqa (Jordanie) ; huit agents de soins de santé faisaient partie des onze personnes affectées, et l'un d'eux est décédé ultérieurement. La cause de cette flambée était inconnue à l'époque et l'étude épidémiologique menée immédiatement après la flambée, comprenant des analyses de laboratoire, n'a pas permis de tirer de conclusions. Après la découverte d'une infection par le nouveau coronavirus dans la péninsule arabique en septembre 2012, des échantillons respiratoires et sériques prélevés chez des patients de cette flambée, et qui avaient été conservés, ont été réanalysés et le diagnostic d'infection par le nouveau coronavirus a été confirmé chez deux patients décédés. Le présent article présente les résultats épidémiologiques de l'étude rétrospective menée en novembre 2012 et souligne la probabilité d'une transmission nosocomiale de l'infection par le nouveau coronavirus en milieu de soins. Au total, deux cas confirmés en laboratoire et onze cas probables ont été identifiés à partir de cette flambée ; dix de ces patients étaient des agents de soins de santé et deux patients des membres de la famille de cas. 


\section{Introduction}

In April 2012, an outbreak of acute respiratory illness was reported by the Ministry of Health $(\mathrm{MOH})$ in Jordan in an intensive care unit (ICU) of a hospital in Zarqa. Among the 11 people affected were 7 nurses and 1 internist; 1 of the nurses later died [1]. All cases were reported to have had high fever and acute lower respiratory symptoms. An epidemiological investigation, including laboratory tests carried out in the immediate aftermath of this outbreak, was inconclusive and the cause of this outbreak remained unknown.

In September 2012, novel coronavirus $(\mathrm{nCoV})$ infection was identified in a patient from Saudi Arabia and later in a patient from Qatar [2-4]. In October 2012, after the discovery of the $\mathrm{nCoV}$ and following reports of patients with $\mathrm{nCoV}$ infections presenting with similar acute lower respiratory symptoms, the Ministry of Health decided to retest the samples from this outbreak for $\mathrm{nCoV}$ at the United States Naval Medical Research Unit-3 (US NAMRU-3) in Cairo, a World Health Organization (WHO) collaborating centre for emerging infectious diseases. Samples were tested by conventional universal pan-corona virus primers and specific reverse transcription real-time polymerase chain reaction (RT-PCR) for the $\mathrm{nCoV}$ using reagents from the United States Centers for Disease Control and Prevention. Bronchioalveolar lavage and nasal swab extracts from a case, who was a health-care worker (HCW) - an intensive care unit (ICU) nurse-and a convalescent serum sample from a second case, who was a student, tested positive for $\mathrm{nCoV}$ by RT-PCR. Accordingly 2 laboratory-confirmed cases of $\mathrm{nCoV}$ infections were officially notified to WHO by the Ministry of Health in Jordan [5]

Following these positive test results, the $\mathrm{MOH}$ Jordan, together with WHO, fielded a team in Zarqa from 28 November to 7 December 2012 to conduct a retrospective investigation of this outbreak. This paper presents the epidemiological findings of this outbreak investigation.

\section{Methods}

\section{Settings}

The field investigation was carried out in Zarqa, which is the second largest city in Jordan with a population of about 1 million. The city is located $25 \mathrm{~km}$ northeast of the capital, Amman. There are 3 public and 3 private hospitals in the city, of which the Zarqa hospital is the oldest and largest public hospital, with a capacity of 300 beds including 6 beds in the coronary care unit (CCU) and 6 beds in the ICU.

\section{Epidemiological investigations Case definition}

For the purpose of retrospective investigation a probable case definition was developed, defined as "any case admitted in Zarqa hospital or their close contacts, who complained of fever and dry cough with radiological evidence of pneumonia during the period from 15 March to 30 April [2012]". For the purpose of the investigation, a close contact was defined as "anyone who provided care to a laboratory-confirmed case, including a HCW or family member, or who had other similarly close physical contact", as recommended in the WHO interim surveillance recommendations for human infection with $\mathrm{nCoV}$ [6].

\section{Patient interviews}

The team visited the Zarqa public hospital as well as 2 other hospitals to which patients were referred during the outbreak in April 2012. Medical records were retrieved and reviewed for all patients with severe acute lower respiratory infections admitted to either the ICU or CCU in Zarqa hospital from 15 March to 30 April. During the visit, interviews were conducted with all the probable cases, HCW and some of the close contacts of both the laboratory-confirmed and probable cases, and key epidemiological and clinical information were collected including their history of contact with other laboratory-confirmed cases. The investigation was targeted at potential modes of acquisition of the infection. The questionnaire contained questions about the early course of disease, social status, living conditions, profession, hobbies and regular activities, exposure to animals, eating habits and contact with individuals with respiratory illness in the 10 days before the onset of illness.

\section{Contact investigations}

The family members of the 2 laboratoryconfirmed cases could not be contacted and no information was collected on the duration or frequency of contact with the laboratory-confirmed cases.

\section{Laboratory investigations}

The hospital laboratory was searched for availability of any other stored respiratory or blood samples from the additional cases reported in this outbreak in April 2012. No such samples were available.

\section{Results}

\section{Epidemiological investigation of the initial cluster}

For the description of this outbreak, all listed cases from the outbreak were considered as probable if no laboratory conformation were available. A total of 13 cases were identified that matched the case definition developed for this investigation. The total number of laboratory-confirmed cases was 2 , while the remaining 11 cases were defined as probable. Of these 13 cases, 10 were HCW in the CCU or ICU, medical or emergency ward in the Zarqa public hospital (Table 1). The 3 non HCWs were a student, a brother of the deceased female nurse and the mother of a male nurse. 


\begin{tabular}{|c|c|c|c|c|c|c|c|c|}
\hline Case no. & $\begin{array}{l}\text { Age } \\
\text { (years) }\end{array}$ & Sex & $\begin{array}{c}\text { Date of } \\
\text { onset }\end{array}$ & $\begin{array}{l}\text { Date of } \\
\text { admission }\end{array}$ & $\begin{array}{c}\text { Date of } \\
\text { discharge/ } \\
\text { death }\end{array}$ & Occupation & Outcome & Classification \\
\hline 1 & 25 & Male & 21 Mar & $4 \mathrm{Apr}$ & $25 \mathrm{Apr}$ & Student & Deceased & Confirmed case \\
\hline 2 & 30 & Male & $30 \mathrm{Mar}$ & $8 \mathrm{Apr}$ & $23 \mathrm{Apr}$ & Nurse & Alive & Probable case \\
\hline 3 & 40 & Female & $2 \mathrm{Apr}$ & 9 Apr & 19 Apr & Nurse & Deceased & Confirmed case \\
\hline 4 & 60 & Male & $2 \mathrm{Apr}$ & $\begin{array}{l}\text { Refused } \\
\text { admission }\end{array}$ & - & $\begin{array}{l}\text { Physician, } \\
\text { internist }\end{array}$ & Alive & Probable case \\
\hline 5 & 29 & Male & $11 \mathrm{Apr}$ & $15 \mathrm{Apr}$ & $21 \mathrm{Apr}$ & Nurse & Alive & Probable case \\
\hline 6 & 33 & Male & $12 \mathrm{Apr}$ & 14 Apr & $21 \mathrm{Apr}$ & Nurse & Alive & Probable case \\
\hline 7 & 28 & Male & $13 \mathrm{Apr}$ & $17 \mathrm{Apr}$ & $21 \mathrm{Apr}$ & Nurse & Alive & Probable case \\
\hline 8 & 45 & Male & $14 \mathrm{Apr}$ & $17 \mathrm{Apr}$ & $24 \mathrm{Apr}$ & $\begin{array}{l}\text { Road technician } \\
\text { (brother of case 3) }\end{array}$ & Alive & Probable case \\
\hline 9 & 46 & Male & $15 \mathrm{Apr}$ & $16 \mathrm{Apr}$ & $21 \mathrm{Apr}$ & Nurse & Alive & Probable case \\
\hline 10 & 25 & Male & $15 \mathrm{Apr}$ & $18 \mathrm{Apr}$ & $21 \mathrm{Apr}$ & Nurse & Alive & Probable case \\
\hline 11 & 53 & Male & $18 \mathrm{Apr}$ & $21 \mathrm{Apr}$ & $23 \mathrm{Apr}$ & $\begin{array}{l}\text { Physician, } \\
\text { internist }\end{array}$ & Alive & Probable case \\
\hline 12 & 28 & Female & 19 Apr & $\begin{array}{l}\text { Refused } \\
\text { admission }\end{array}$ & - & Nurse & Alive & Probable case \\
\hline 13 & 60 & Female & $26 \mathrm{Apr}$ & 1 May & 5 May & $\begin{array}{l}\text { Housewife (mother } \\
\text { of case } 2 \text { ) }\end{array}$ & Alive & Probable case \\
\hline
\end{tabular}

The investigation and the epidemic curve suggested 2 phases to the outbreak (Figure 1). The initial phase consisted of 4 cases: 2 laboratory-confirmed cases (who died) and 2 probable cases (who recovered from their illness). For investigation purposes, emphasis was put on the initial phase in order to better understand the potential origin of the disease.

\section{Case 1 and exposure history}

Based on the reported date of onset of symptoms case 1 was a 25 -year-old university student who had onset of symptoms on 21 March 2012. He was among the 4 cases identified in the initial phase of this outbreak. He had cough for a week followed by fever and shortness of breath. He was admitted to the regular medical ward in Zarqa public hospital on 4 April with an initial diagnosis of pneumonia. His X-ray showed right lung consolidation and he was later treated for pericarditis. He was then transferred to the CCU a day after admission and later transferred to Prince Hamzah hospital in Amman for further treatment, where he was admitted to the CCU and then to the ICU isolation room on the second day of his arrival and was intubated. His condition deteriorated and he eventually died on 25 April. The patient had no travel history and had no reported direct contact with animals or with persons with severe respiratory illness in the 10 days before the onset of his illness. A total of 3 close contacts of case 1 were identified (1 household and 2 HCW contact). The household contact, who was the patient's mother, did not report any respiratory symptoms, while $2 \mathrm{HCW}$ developed respiratory symptoms (hereafter referred as case 2 and case 3 ) that progressed to severe illness requiring hospitalization.

\section{Case 2 and contacts}

Case 2 was a 30-year-old male CCU nurse in Zarqa hospital with an estimated onset of symptoms on 29 March 2012. This was a probable case, who recovered. The patient had no travel history and no reported contact with animals in the 10 days before the onset of illness. It was reported that he was in direct contact with case 1 as he was caring for him in the CCU; however, it was not clear why his date of onset of symptoms was 5 to 6 days before case 1 was admitted in the hospital. He was admitted to the CCU of Zarqa hospital on 8 April with shortness of breath and bilateral pneumonia. $\mathrm{He}$ was transferred to the CCU of Islamic hospital on 12 April and was discharged in good condition on 23 April. A total of 2 close contacts (household contacts) were identified for case 2 . One was the mother of case 2 (hereafter referred to as case 13) and developed respiratory symptoms which required hospitalization. The other household contact, who was a brother of case 3 , had also cared for him but did not report any respiratory symptoms in the 10 days post-exposure.

\section{Case 3 and contacts}

Case 3 was a 40-year-old female ICU nurse at the Zarqa hospital with onset of symptoms on 2 April 2012 and was a laboratory-confirmed case who later died. From the limited information 


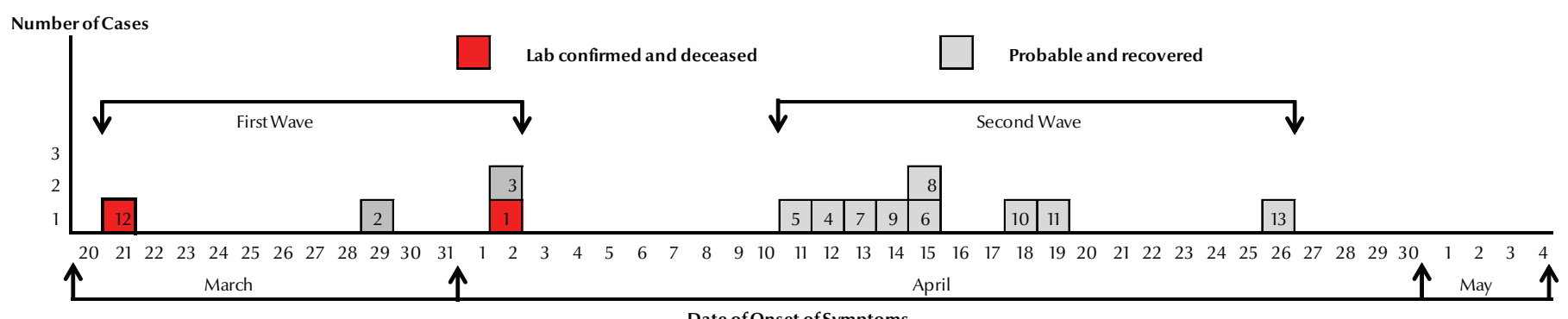

Date of Onset of Symptoms

Figure 1 Epidemic curve of confirmed and probable cases of novel coronavirus infection, Zarqa, Jordan, 20 March to 4 May 2012

available, there was no travel history or contact with animals in the 10 days before the onset of her illness. She was admitted to the ICU of Zarqa hospital on 9 April with right-sided pneumonia. She was transferred to the ICU of Islamic private hospital in Amman on 14 April, was intubated the following day and died on 19 April with a disseminated coagulopathy. A total of 4 close contacts of case 3 were identified (all household contacts), one of whom was a brother of case 3 (hereafter referred to as case 9) and developed pneumonia in the 10 days post-exposure.

\section{Case 4 and contacts}

Case 4 was a 65-year-old medical doctor, head of the internal ward, a probable case who recovered. The onset of symptoms was on 2 April 2012 with fever and fatigue. There was no travel history or contact with animals in the 10 days before the onset of his illness His chest $\mathrm{X}$-ray showed bilateral pneumonia. He refused admission to the hospital and took self-care at home. No respiratory disease was reported in any of his household contacts.

\section{Epidemiological investigation of the secondary phase}

The secondary phase consisted of 9 probable cases who all developed pneumonia? and recovered (Figure 2).

\section{March to May 2012}

The onset of symptoms was between 11-19 April 2012 for 8 cases and was 26 April for the last reported probable case. Seven of these probable cases were HCW (2 CCU nurses, 1 internist, 1 nurse in the internal ward and 2 nurses working in the emergency ward) and 2 cases were relatives of HCW (mother of case 2 and brother of case 3). Based on the available information all of them were likely to have had significant contact with at least 1 of the 2 confirmed cases, apart from the mother of the probable case 2 , for whom a contact to a confirmed case was not documented in the 10 days before onset of symptoms. To prevent stigmatization of patients the HCW reported that they did not use any personal protective equipment apart from gloves when caring for the patients.

\section{Investigation for additional cases}

The initial outbreak investigation report stated that there was no unusual pattern of community-acquired respiratory disease noted in the community or other hospitals. It was not possible to validate this information during the investigation. Review of the ICU admission log book in Zarqa hospital revealed 6 other cases for whom admission could have been due to respiratory symptoms and whose files were reviewed. While 5 cases were discarded due to irrelevant symptoms, only 1 case, a 22-year-old patient with Down syndrome, had signs of an acute respiratory infection at admission and later died. His date of onset of symptoms was at the end of March 2012. No laboratory results for $\mathrm{nCoV}$ were performed for this case. Interviews with nurses from the CCU revealed 2 other non-Jordanian patients with signs of respiratory infection. Review was only possible for 1 of them and this did not show any documented acute respiratory disease.

All admitted cases identified in this cluster were transferred from Zarqa hospital to 2 other hospitals in Amman (Islamic hospital and Prince Hamzah hospital). The 2 referral hospitals were asked to analyse their discharge statistics (using International Classification of Diseases, version 10 codes) for the month of March to May 2012 and 2011. The information retrieved from one of the referral hospitals (Islamic hospital) suggested an increase in the number of visits to that hospital of patients with pneumonia, with 74 cases in April 2011 compared with 205 cases recorded in April 2012. No further information was available explaining this apparent rise in cases of severe acute respiratory infection.

\section{Exposure of the patients}

Some information on exposure from the initial phase of the outbreak was available for the $3 \mathrm{HCW}$ and not for the deceased patient. All of the HCW had no history of travel or contact with animals. The only known fact was that case 3, with onset of symptoms 


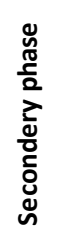

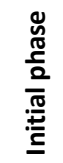

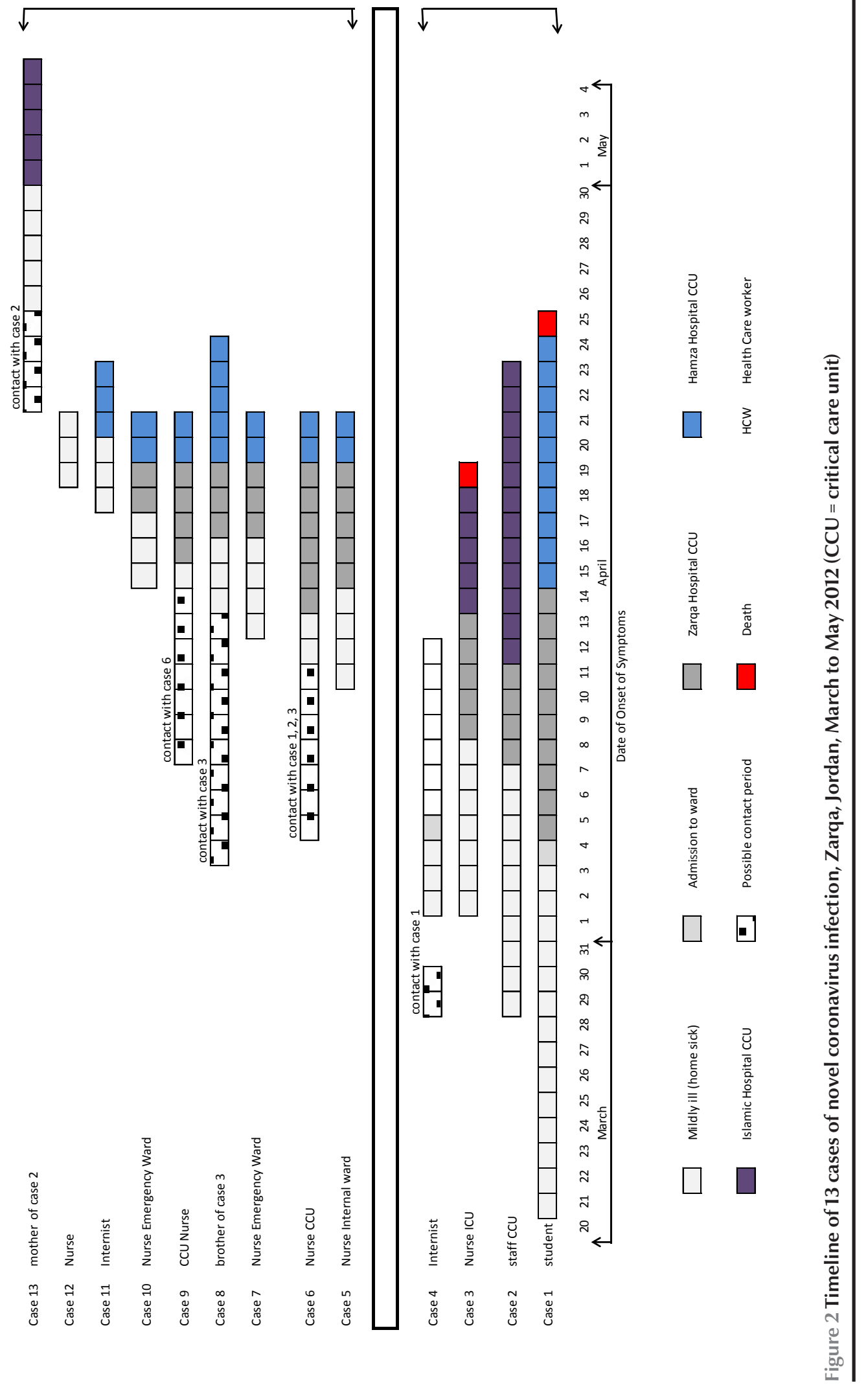


bronchoalveolar lavage from 9 patients were tested at US-NAMRU-3 by RTPCR for coronaviruses (229E, HKU1, NF69, OC), parainfluenza viruses 1-3, adenovirus, human metapneumovirus and for severe acute respiratory syndrome (SARS) virus by nested PCR, using published sequences. Except for case 1, where the RNA extracts from nasopharyngeal swabs were weakly positive for CV 229E by RT-PCR, all other cases were negative for all viruses tested. Following the discovery of $\mathrm{nCoV}$, another set of these stored samples (5 serum samples and 2 nasopharyngeal swabs and 2 bronchoalveolar lavages) were sent to US NAMRU-3 for retesting in October 2012. No additional samples from the outbreak were available for $\mathrm{nCoV}$ testing in during the autumn in 2013. The US NAMRU-3 also tested another 234 nasopharyngeal samples that were collected from the severe acute respiratory infection sentinel surveillance sites from April and October 2012 and all samples tested negative for $\mathrm{nCoV}$.

\section{Discussion}

In this report of the Jordan 2012 $\mathrm{nCoV}$ outbreak we present evidence of limited person-to-person transmission of $\mathrm{nCoV}$ following contact but it seems that transmission did not occur frequently. The secondary cases that were detected had a putative incubation period within 10 days of reported contact with cases. The secondary cases were mostly HCW, who most likely acquired the infection in health-care settings. However, $\mathrm{nCov}$ was not detected among the close contact of the index case or among the 4 close contacts of the 2 other cases reported in the initial phase. These findings suggest that although person-to-person infection is possible, there is no evidence at present of sustained person-to-person transmission of $\mathrm{nCoV}$ in relation to this cluster. on 2 April 2012, had her sister visiting from Saudi Arabia 1 month before the onset of symptoms. No information was available regarding residence and or health status of the visiting sister. The 2 probable cases in the initial phase of this outbreak had contact with the laboratory-confirmed cases in the CCU of Zarqa hospital, while the 2 other probable cases in the second phase of this outbreak-case 13 and case 8were the household contacts of cases 2 and 3 respectively. It was also possible that the $7 \mathrm{HCWs}$ who were the probable cases in the second phase of this outbreak had some contacts with the 2 laboratory-confirmed cases of the first phase; however, the investigation could not establish this link.

\section{Age and sex}

The median age of patients was 33 years (range 25-65 years). Males accounted for $77 \%$ of the 13 cases.

\section{Clinical picture}

The earliest date of onset of symptoms was 21 March 2012 and most cases (70\%) were described as having cough followed by high fever. The duration of admission for admitted patients (2 patients refused admission) ranged from 3-17 days with a mean of 9 days. The white blood cell count in a majority of cases was disproportionately low considering the extent of infection and body temperature of the patients. The chest X-rays showed evidence of singlelobular, bi-lateral or multi-lobular pneumonias. No sequelae were reported in the recovered patients. No case had renal failure. Case 1 had a pericarditis with huge fluid accumulation.

\section{Laboratory investigations: patient samples}

During the outbreak of acute respiratory illnesses in April 2012, the US NAMRU-3, Cairo, was requested to support the laboratory investigation of cases reported from this outbreak. Nasopharyngeal swabs and 1
For the index case of this outbreak, we had 2 main hypotheses. Case 1 , who was a student and admitted with pneumonia and pericarditis, was the first $\mathrm{nCoV}$ patient and case 2 , who was a HCW became infected from him. However, there remained the question how the HCW was exposed, as the index case's admission was after the $2 \mathrm{HCW}$ had already developed symptoms. It is possible that there might have been contact between the index case and any of these HCW in the outpatient clinic before the index patient's admission or that each case had different exposure histories that could not be identified or established.

Another hypothesis was that case 2 was the initial case and that he infected his colleagues as well as case 1 , who he was caring for. The $\mathrm{HCW}$ was present at work while he was already symptomatic with cough and fever. He also would have been in contact with cases 3 and 4 at his workplace. This would suggest that case 1 was admitted due to signs and symptoms of a different disease and had acquired the infection while in the CCU at Zarqa hospital. If this is the case, the question then is: from where did case 2 contract the infection and why were only HCW infected (beside the 1 patient and relatives)? The hospital set-up, as well as the stated contact of the HCW while caring for symptomatic cases (i.e. without using precautions to prevent transmission) means that human-human transmission was very likely to have occurred. Further possibilities are that there was a common source of infection outside the hospital, but again we would expect more cases outside the hospital, or that there was yet another patient who would have infected the HCW as well as case 1.

For the secondary phase, personto-person transmission in health-care settings seemed very likely, and close contact with respiratory secretions seems to be the most likely route of transmission, despite the limited information available. Based on the available 
information, the outbreak seems to have been limited to the direct contacts of patients (brother and mother). It is unclear if there might have been more cases with less severe presentations that were not admitted to the hospital and eventually might have been excluded from the list of probable cases, as the definition for the probable case did not include those who presented with mild illness and were not admitted. The limited transmissibility is consistent with the data available to date, with 2 other reports of small, self-limited clusters of severe disease in the Eastern Mediterranean Region in a household setting [7] and in the United Kingdom in a household setting [8]. Furthermore, intensive follow-up of the close contacts of 2 other cases imported to European countries has failed to demonstrate onward transmission $[8,9]$.

Our investigation had some important limitations. The main limitation was recall bias, as the epidemiological investigation was conducted 7 months after the outbreak. The complexity of social perceptions made access and data collection from the relatives and other contacts extremely difficult. Other factors were the death of 2 possible index cases, the unavailability of stored respiratory specimens for the majority of patients to be tested for $\mathrm{nCoV}$, the absence of serological tests for confirmation of previous infection with $\mathrm{nCoV}$ and the case definition of the outbreak which excluded patients without radiological evidence of pneumonia.

\section{Conclusion and recommendations}

This outbreak of $\mathrm{nCoV}$, with evidence of likely transmission in a health-care setting, together with our observation of limited secondary transmission, highlights the importance of ongoing vigilance and rapid investigation of cases or clusters of severe respiratory illness, including HCW, with pneumonia from any area that match the current case definition from WHO [6].
Further work is required to determine how widely $\mathrm{nCoV}$ is circulating in the area. To establish the final links and to investigate the risk factors for transmission, a seroepidemiological study needs to be conducted in various population groups-HCW, among families and the community-to understand the extent of this outbreak. Until that time, it is important to strengthen both the epidemiological and virological surveillance for severe acute respiratory infections in Zarqa hospitals and to detect any changes over time.

\section{Acknowledgements}

The Jordan Ministry of Health expresses it is appreciation and thanks to the World Health Organization Regional Office for the Eastern Mediterranean, the World Health Organization Jordan country office, the United States Naval Medical Research Unit-3 in Cairo and the Centers for Disease Control and Prevention, Atlanta, Georgia for their assistance and support.

\section{References}

1. Severe respiratory disease of unknown origin-Jordan-outbreak in ICU. Communicable Disease Threats Report, week 18, 29 April-May 2012 (http://www.ecdc.europa.eu/en/publications/Publications/CDTR\%20online\%20version\%204\%20 May\%202012.pdf, accessed 9 May 2013).

2. Zaki AM et al. Isolation of a novel coronavirus from a man with pneumonia in Saudi Arabia. New England Journal of Medicine, 2012, 367:1814-1820.

3. Severe respiratory illness associated with a novel coronavirus-Saudi Arabia and Qatar, 2012. Morbidity and Mortality Weekly Report, 2012, 61(40):820-820.

4. Bermingham A et al. Severe respiratory illness caused by a novel coronavirus, in a patient transferred to the United Kingdom from the Middle East, September 2012. Eurosurveillance, 2012, 17(40): pii: 20290.

5. Novel coronavirus infection-update. 30 November 2012. World Health Organization [online] http://www.who. int/csr/don/2012_11_30/en/index.html, accessed 7 May 2013).

6. World Health Organization. Interim surveillance recommendations for human infection with novel coronavirus as of 18 March 2013 (http://www.who.int/csr/disease/coronavirus_infections/InterimRevisedSurveillanceRecommendations_nCoVinfection_18Mar13.pdf, accessed 9 May 2013)

7. Albarrak AM et al. Recovery from severe novel coronavirus infection. Saudi Medical Journal, 2012, 33:1265-1269.

8. Health Protection Agency (HPA) UK NCoV Investigation team. Evidence of person-to-person transmission within a family cluster of novel coronavirus infections, United Kingdom, February 2013. Eurosurveillance, 2013, 18(11):pii 20427.

9. Buchholz $U$ et al. Contact investigation of a case of human novel coronavirus infection treated in a German hospital, October-November 2012. Eurosurveillance, 2013, 18(8):pii 20406. 